\title{
How to Make the Optimization Model for Parking Lots in Taipei
}

\author{
Miao-Sheng Chen ${ }^{1} \&$ Meng-Feng Lin $^{1}$ \\ ${ }^{1}$ Professor, Department of Business, Administration, Nanhua University, Taiwan \\ ${ }^{1}$ Ph.D. Candidate, Department of Business Administration, Nanhua University, Taiwan \\ Correspondence: Meng-Feng Lin, Ph.D. Candidate, Department of Business Administration, Nanhua University, \\ Taiwan. E-mail: mysteventsai@yahoo.com.tw
}

Received: November 10, 2017

Accepted: June 4, 2018

Online Published: June 15, 2018

doi:10.5539/ijbm.v13n7p262

URL: https://doi.org/10.5539/ijbm.v13n7p262

\begin{abstract}
Due to the rapid urbanization, motorization and the high density of most urban structures, the parking challenge in Taipei is getting worse. Although public transit systems have advanced as an economical and friendly alternative to cars, people prefer to drive the car to their destination because it takes less time and is more flexible for many trips. As a result, the significant shortage of parking spaces in cities creates a problem for drivers. The lifetime and stability of the mechanism from "nothing" to "something" depend on whether or not the interchangeability of such mechanism can catalyze subsequent operations spontaneously as well as the degree of catalytic power. If the mechanism possesses spontaneous catalytic power for sustainability, and the catalytic process has the "good" to benefit other people without compromising your own interest, the formation of this mechanism will be regarded as "good formation".
\end{abstract}

Keywords: Optimization, Mechanism, Parking lots

\section{Research Background}

In accordance with IHS Automotive analysis, the demand for parking spaces has increased dramatically because of the increase in global vehicles. Furthermore, many people in adjoining areas, including New Taipei City, Keelung, and Taoyuan, drive into Taipei for work every day, further straining the source of parking lots. There are a total of 1.6 million autos in Greater Taipei, including Taipei, New Taipei, and Keelung. According to the statistics of the Ministry of Communications, there are about 800,000 vehicles registered in Taipei City (not including cars from other counties or cities). There are about 670,000 parking spaces for public and private parking spaces. However, there are only about 130,000 parking spaces. More than $70 \%$ of them belong to private parking spaces, and the idle rate is about 30 to $50 \%$.

In other words, about 460,000 parking spaces are self-used, and most of them are idle condition. The cars without parking lots are parked on roads or in residential area, which makes the already vulnerable 'capillaries' of roads weaker, even makes fire control passageways blocked in some places. From the aspect of supply and demand, the parking space in Taipei is indeed insufficient. However, the actual problem is that the private and idle parking spaces are not used well. And this situation will become more and more serious. What would happen if Taipei City suddenly had 460,000 parking lots. At the same time, it is hard to create new parking lots because of the constant growth of population density. The significant shortage of parking lots in cities creates a tough problem for drivers. Expand this logic, and it's accepted to think that parking on a much bigger scale induces more driving across cities. But this is an extremely hard thing to prove: When cities pave more parking lots, does it make people drive more? When you're sitting in traffic jam by other cars, is easy parking in part to blame? There's lots of prove that the two go hand in hand. Past researches have found that parking availability at home is powerfully associated with car ownership and use. And more parking at the office is correlated with more employees driving to work alone.

Commuters who work in Taipei, for example, are also more likely to drive in when they have parking to return to after dark. It's a offensive dispute, though, that parking causes driving, and if this were true, a lot of city policies would look sort of backwards. When cities think they're simply accommodating all the driving we do — by, for starters, requiring apartments and businesses to build parking lots — they're indeed encouraging that driving in the first place. "Is there a reason parking could influence driving?" asks by Taipei City Deputy Mayor Chen, a senior gonvernment officer in Taipei City Government. "On a city-wide scale it does make sense that the 
complete cost and convenience of parking in that place affects driving patterns, as anyone who's lived in a parking-restricted place knows." If owners of new homes are willing to purchase road land from private owners and transfer them to the government, the government can increase the floor area restrictions based on the scale of the transferred land property as incentives for owners of new homes. For drivers, one problem is to search for available parking lots quickly and locate the space that is the closest to the goal. In this research, an innovative parking lot in Taipei is being used as a research site and demonstration project to show how small alterations to parking lot designs can dramatically improve the tough problem.

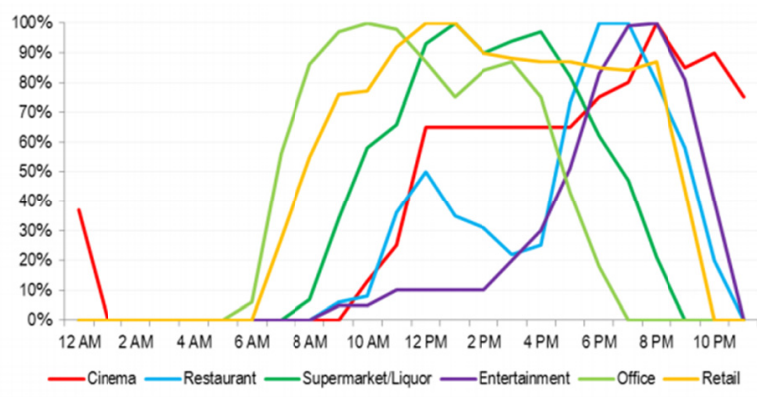

Figure 1. Example of parking requirement on weekdays

\section{Research Methodology}

For a long time, urban traffic jam and traffic confusion have been troubling urban economic and social progress. To figure out these problems, we need to take some kinds of measures. On the one hand, increase the supply of transportation facilities. On the other hand, reinforce the demand management to guide correctly and control the transportation requirement. Taipei need to carry out strict restriction policy to control the growth rate of car ownership and parking demand and prevent further worsening of supply-demand. Under actual situations, it is impossible to supply sufficient parking lots in a short period of time. Aggravation is expanding. In an official survey conducted over the past year, nearly four-fifths of respondents said that parking had become a "bugbear". They agree that they lived in places with frequent traffic jams, a tough problem for Taipei. Where a car is found illegally parked, the police will take a photograph and ticket it. The photograph is entered into the police computer system. Car owners will receive tickets soon. Even if the ticket is lost or destroyed, the computer record and photo remain and the fine must be paid before the car owners drivers licence can be renewed. Like other traffic demand designs, parking demand is based on relevant land use conditions during peak and non-peak periods. Distinct but corresponding patterns, such as "office parking" that is generally bare in the evenings and on weekends and "residential parking" that is generally filled in the evenings, offer an occasion for Taipei to better satisfy residents and commuters without increasing supply. Shared parking is a land use/development policy that optimizes parking capacity by allowing complementary land uses to share spaces, rather than producing separate spaces for separate uses.

To facilitate the efficiency of parking searching guidance, numerous studies and systems have been conducted to guide drivers to the parking vacancy at the adjacent parking lot. While the Taipei city government collected public-owned road land property for public demands like parking. A practical parking policy is created by combining different prices and types in order to offer a variety of services that satisfy different demands of drivers. A good policy can thus attract more drivers and better utilize parking spaces. This discourse process of philosophical attitude is considered as a deductive method. To meet the shortage, property managers, developers, businesses and local government like to build more parking facilities which encourages driving. By increasing parking fees, parking needs are reduced. Drivers will choose to go elsewhere or away from their destination. Increase on-street parking is an easy solution and generates more revenue for the local government. The only disadvantage is a high risk of accidents and problems for cyclists. Spaces in the corners and the edges of the parking lot can be used to create more space. For small vehicles, the area can be sized. If the government wants to interfere in the property of citizens, the government must contribute to the citizen's property first. 


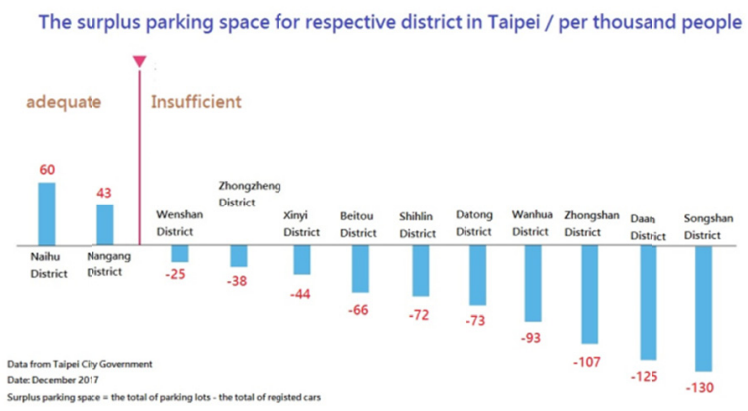

Figure 2. The surplus parking space for respective district in Taipei/per thousiand people

\section{Research Content}

\subsection{The Method of Recycling Idle Land}

It is easy to see that all motorcycles are concentrated at the traffic lights in Taipei city, if one day, when all those motorcycles have become cars, it is going to be a kind of "murder" with the traffic condition. That was obvious to anyone very much. What was not foreseen feasibly was that as people moved up to cars, many more motorbikes came in right behind them. At present, all cars will not only become traffic problems.

Motorcycles account for a quarter or less of car space, especially SUVs. Cars cannot be like many motorcycles stopped on the sidewalk outside the store. In addition, most of the vehicles parked in the narrow lanes of Taipei block pedestrians' free activities.

At the same time, the problem of parking spaces is something that should really have been foreseen by the Taipei city leaders. It is bad enough in Hong Kong, where apartments are small - and if you are unfortunate enough to die, it will cost you (or your relatives) an arm and a leg to be able to inter you in a plot of land, and even a niche for your ashes will cost lots of money.One of the most jammed areas in terms of both traffic situations and parking is Taipei's Neihu District, where about 200,000 commuters enter on a daily basis, usually in their own vehicles and with many heading for work in the Neihu Technology Park. The condition is also tremendously serious in older sections in Taipei, such as the Wanhua, Datong, and Shilin districts, where many buildings lack their own parking lots. In some communities, the parking shortage has sparked a ascent for access to public parking spaces available for rent. In the Lanya li neighborhood in Shilin's Tianmu, for example, local citizens line up throughout the night on the 25th of every month, usually bringing folding chairs and covering themselves with overcoats and wholesales during late fall and winter, for the right to buy parking tickets - valid for one month - to use the 150-plus spaces in adjoining public parking spaces. Local residents can enjoy up to $30 \%$ discount. Owners of some of the collectively owned road-owned lands may voluntarily organize a collective housing management committee to manage the use of land on collective housing roads, and clearly use the targets, especially the planning of parking spaces in the housing community (Valleley, 1997). In the real world, it is hard to spread the smart parking service to all customers. First, there is a group of drivers who are just ad hoc users of the parking lot. They may not apply for the smart parking service because they may not come to the parking lot again in the future. Typically, the user for the parking spaces are limited to the owners of congregate housing road lands or their relatives.

In general, the user of a parking space is limited to the owner of a collective housing road or their relatives (Steierwald \& Kunne, 1997). Generally speaking, the lottery will be used to determine the user of the parking space during the rental period (Irmscher, 2007). After the lease period is over, it must be redrawn. Even if the parking space rental income belongs to the shared landowner, most residents' community management committees will convert the income into public deposits to maintain the safety, sanitation/cleanliness, landscape, or other needs of the housing community. Of course, parking spaces organized by the residents' community management committee must not interfere with road traffic. The question is who has the right to decide: Does parking disrupt road traffic? Should it be decided by the owner of the common land? A fallacy can be found in the answers to the following questions (Mei \& Tian, 2011). Public-use property cannot be allocated or divided. Only the priority of service targets and the rules of use can be assigned for using public-use property. Public use lands cannot be allocated. Only the priority of service objects and usage rules can be assigned to the use of public property. The literal meaning is that road land can only be used for road-related purposes. Therefore, road land belongs to public use property. According to the problem point of view, road land cannot be allocated or 
divided. This can be explained by the following assumptions. Assume that road land property is owned by ten people (Caicedo, 2009). Everyone will have an equal share of one/tenth. Is it possible for everyone to take his/her own share of property for private use? The answer is no. The reason is because roads must maintain their integrity in order to function properly. For summarizing the content of the problem and the proof of the problem, the following conclusions can be drawn.

\subsection{The Demand for Constructing Public Parking Lots on Road Lands}

In order to lessen the parking shortage, the Taipei City Government has been encouraging organizations and schools to open parking lots for use by citizens after class. Up to now, 105 such offices and 67 schools have done so, creating about 25,000 parking spaces for part-time use by outsiders. The number is expected to increase by the end of this year, as more agencies and schools join the ranks. Currently, cars spend around $95 \%$ of the time parked, and only $5 \%$ of the time in use. Huge strips of cities, either in parking lots, garages, or street parking spaces, are used as storing for cars (while, at the same time, many cities struggle to find enough land to build housing for request) (Geng \& Cassandras, 2011). For areas with high parking demand, Taipei city government surveys idle city-owned lands and proactively manages the efforts of other land management authorities under Taipei city government to offer unused lands for the building of temporary off-street parking lots, thus solving the problem of insufficient downtown parking and better utilizing the land resources. A separate imagining shows how space is allocated in Taipei between modes of transit, and how that compares to how people actually get around. Obviously, use tends to follow the available infrastructure. If most people drive, That's most likely because most space is currently dedicated to cars. "In urban planning, there is this notion that once you build infrastructure then it will be used. If there are highways, people drive; if there are separated bicycle lanes, more people will begin to bike. We were thinking about how to make it most instinctively and accessibly comparable. Fundamentally, what we needed to do was lessen all of the space that is out there-all of these convoluted buildings-to just one measurement (Banerjee, \& Al-Qaberi, 2011). We can see that the owners of road land cannot promote the right to use these properties, and the basic meaning of "property rights" will be violated. In the suburbs, rivers tend to change course due to climate change. Establish minimum off-street parking requirements in zoning regulations and development policies, and raise these minimums as needed to accommodate growth in parking demand. It is helpful to coordinate such requirements among jurisdictions in a region in order to avoid conflicts. Design streets with parking lanes. Convert traffic lanes to parking lanes. Minimize restrictions for on-street parking. Convert parallel to angled parking. In smaller commercial centers, on-street parking may provide most of the parking supply. Share parking among a group of employees or residents, rather than assigning to individuals. For example, 50 employees or residents can usually share 30-40 parking spaces without problem, particularly if implemented in conjunction with other commute trip reduction and location efficient development strategies. After these spaces are diverted, they may invade private land (Banerjee, \& Al-Qaberi, 2011).

The government should invest in the construction of public parking spaces on suitable shared road land. Parking space rental income will be distributed to owners in proportion to shared road land. Deciding how many parking spaces already exist in the area and analyze the use of different time and space. The city can develop a shared parking forecast based on how much parking demand it is willing to satisfy across different time periods as part of its mode share goals, breaking the shared parking system down by weekday peaks, evening peaks and weekend peaks. Shared parking may be beneficial to developers, businesses, and governments, but it requires time and careful investment. It is a process that requires constant review and a coordinating body that can be a broker and analyze how spaces continue to be used (Geng \& Cassandras, 2011).

\begin{tabular}{|l|l|l|}
\hline Weekday Peaks & Evening Peaks & Weekend Peaks \\
\hline Banks & Auditoriums & Religious institutions \\
\hline Schools & Bars and dance halls & Parks \\
\hline Distribution facilities & Residents & Shops \\
\hline Factories & Meeting halls & \\
\hline Medical clinics & Restaurants & \\
\hline Offices & Cinemas & \\
\hline
\end{tabular}

Figure 3. The analysis of peak need of parking 


\section{Conclusion}

The challenge of providing sufficient parking within Taipei area can be amortized over a timeline. That is, if development occurs rapidly, then parking solutions will also need to be provided quickly. After completing the construction of parking spaces on appropriate highway land, the authorities provide benefits to landowners and recalls the arguments and evidence behind the decision of the historical judicial case between the government's road control rights and the intergovernmental road control rights. But as a minimum, Taipei has a very well-organized public transport service - not only MTR and buses, but minibuses and taxis of course. Real, a permanent place to keep your car will cost you about a third of the price of an apartment, but it is easy to completely opt-out, because it is simply more convenient to go by public transport. Taipei city government should strengthen the plan and construction of parking spaces in residential area and take complete utilization of the corner and idle land of residential area. Based on the green space, public square and etc., the construction of subterranean parking should be encouraged modified local conditions. In addition, Taipei city government should improve the construction patterns of residential parking facilities to prevent the gap of parking lots from burgeoning. Another good idea would be stricter enforcement of no-parking zones, which would hold excess parking demand in the center of Taipei and encourage people to use public transport. Finally, Effective use of existing parking infrastructure, reducing the burden on developers to build more parking and support for transit-oriented development are all main benefits for shared parking strategy. Taipei City Government should draw up a plan of shared parking according to this paper.

\section{References}

Banerjee, S., \& Al-Qaberi, H. (2011). An intelligent hybrid scheme for optimizing parking space: A Tabu metaphor and rough set based approach. Egyptian Informatics Journal, 12, 9-17.

Caicedo, F. (2009). The use of space availability information in "PARC"systems to reduce search times in parking facilities. Transportation Research Part C, 17, 73-79.

Chang, H. J., \& Chen, P. Y. (2008). An EOQ Model with Controllable Selling Rate. Asia-Pacific Journal of Operational Research, 25(2), 151-167.

Geng, Y., \& Cassandras, C. G. (2011). A new "Smart Parking"system based on optimal resource allocation and reservations. 14th International IEEE Conference on Intelligent Transportation Systems. Washington, DC, USA.

Irmscher, I. (2007). State of the Art Car Parks in Germany-Certificational and technological aspects. Conference Report VI. City parking in Europe, Berlin.

Leephakpreeda, T. (2007). Car-parking guidance with fuzzy knowledge-based dicision making. Building and Environment, 42, 815-819.

Mei, Z., \& Tian, Y. (2011). Optimized combination model and algorithm of parking guidance information configuration. EURASIP Journal on Wireless Communications and Networking, 94-105.

Polak, J., \& Axhausen, K. (1991). Choice of parking: Stated preference approach. Transportation, 18, 84-90.

Steierwald, G., \& Kunne, H. D. (1994). Stadtverkehrs - Plannung -Grundlagen-Methoden-Ziele, Berlin, 1994.

Valleley, M. (1997). Parking Perspectives - a Source Book for the Development of Parking Policy. London: Landor publishing, London.

\section{Copyrights}

Copyright for this article is retained by the author(s), with first publication rights granted to the journal.

This is an open-access article distributed under the terms and conditions of the Creative Commons Attribution license (http://creativecommons.org/licenses/by/4.0/). 